Research Article

\title{
Landslide Susceptibility in Relation to Correlation of Groundwater Development and Ground Condition
}

\author{
S. N. L. Taib, O. S. Selaman, C. L. Chen, R. Lim, and D. S. Awang Ismail \\ Department of Civil Engineering, Faculty of Engineering, Universiti Malaysia Sarawak, Sarawak, Malaysia \\ Correspondence should be addressed to O. S. Selaman; sosuhaiza@unimas.my
}

Received 20 February 2017; Revised 17 July 2017; Accepted 1 October 2017; Published 17 December 2017

Academic Editor: Andrea Benedetto

Copyright (c) 2017 S. N. L. Taib et al. This is an open access article distributed under the Creative Commons Attribution License, which permits unrestricted use, distribution, and reproduction in any medium, provided the original work is properly cited.

\begin{abstract}
Rainfall is inevitably one of the main factors that trigger landslides. However, not much study has been conducted on the impact of groundwater rise on slope stability. Thus, this study is intended to focus on the rise of the groundwater level from the bottom of the slope which would lead to landslides due to pore pressure development by eliminating other landslide-triggering factors (i.e., infiltration and surface runoff). Saturated sand was used for slope modeling, and sand densities of $1523 \mathrm{~kg} / \mathrm{m}^{3}, 1562 \mathrm{~kg} / \mathrm{m}^{3}$, and $1592 \mathrm{~kg} / \mathrm{m}^{3}$ were tested with a constant slope angle of $45^{\circ}$. Another set of experiments was also performed on slopes having angles of $25^{\circ}, 45^{\circ}$, and $60^{\circ}$ and with a maintained density of sand at $1562 \mathrm{~kg} / \mathrm{m}^{3}$. Through observation, failure was initiated first at the toe of the slope before minor and major slips or total collapse occurs. Dimensions of slip surfaces were measured and included in SLOPE/W for the computation of the safety factor. In conclusion, safety factors are found to be higher in denser soil and in the lowest slope angle. However, faster occurrence of collapse in denser soil was identified and could be contributed by the faster pore water pressure development.
\end{abstract}

\section{Introduction}

Landslide is a high-risk phenomenon that often occurs around the globe either at small or big scale. It has been known as a natural phenomenon, but nowadays, its occurrence is more often due to human activities. The impact of landslides is a threat to human life and could destroy any existing structure or property in its path. Various factors could contribute to the occurrence of landslides, and rainfall is an inevitable triggering factor especially in tropical countries like Malaysia.

From previous researches, it is well known that rainfall has intense effects in producing landslides in the mountainous areas of different countries [1]. Several studies [2,3] suggest that precipitation is one of the important triggering factors that cause landslides. Gofar et al. [4] stated that landslides induced by rainfall are most common in tropical regions where the climatic condition is governed by the wet and dry periods as experienced in Malaysia. They proved that the infiltration process increases the pore water pressure within the slope and reduces suction in the unsaturated regime.
The infiltration of rainwater leads to reduction in soil's shear strength provided by the matric suction, especially in a homogeneous soil slope profile. A two-dimensional infinite laboratory slope model was constructed by Yanusa et al. [5] as in Figure 1 to study the effect of layering two different grades of soil: Grade V and Grade VI on transient suction distribution in a slope. Slope stability analyses were carried out using SLOPE/W to obtain its safety factor. The research work concluded that a capillary barrier occurred in the layered soil system as transformation of particle sizes existed at the soil interface between two layers. The safety factor was found to have improved in the layered system as soil suction was maintained. Nonetheless, if a breakthrough occurs within the system, the safety factor decreases significantly in comparison with a homogenous soil system.

A study by Wang and Sassa [6] stated that, for saturated samples in undrained condition, the greater pore pressure would be built up in looser material. However, they also examined that the soil with greater permeability will have quicker dissipation, thus leading to smaller pore pressure build up. Denser soil with smaller void ratio contributes to lower permeability and also slower dissipation. 


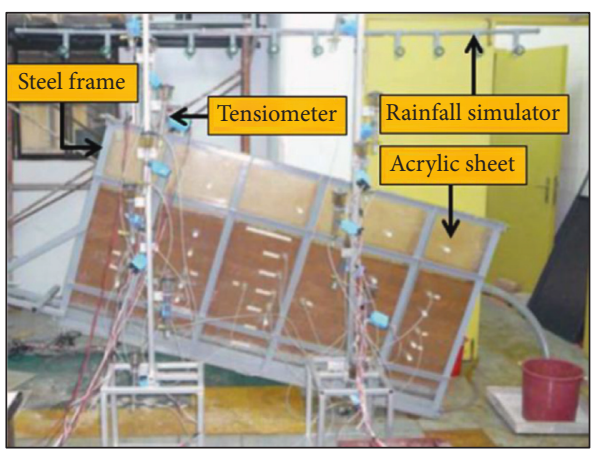

FIgURE 1: Laboratory slope model [5].

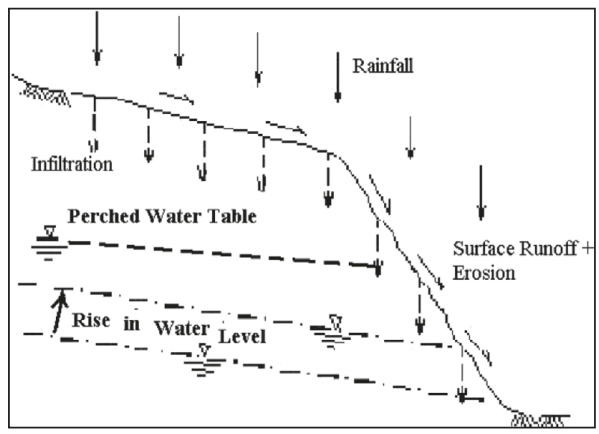

Figure 2: Rainfall induced landslide [8].

Lu et al. [7] revealed that failure initiates more easily at the toe of the slope based on various tests performed at different rainfall intensities which aimed to study pore pressure development in the slope. They studied the relationship between rainfall duration with the initiation of debris flow and rainfall intensity by conducting tests in a box model. It is also concluded that pore water pressure and water saturation in the slope increase with rainfall duration time and rise faster with rainfall intensity. In Figure 2, Gue and Tan [8] indicated that some rainwater shall run off the slope and may cause surface erosion if there is inadequate surface protection. Soil with high permeability as in the figure shall also allow majority of the water to infiltrate into the subsoil and cause water level in the slope to rise [8].

This research focuses on the relation between ground pore water pressure development due to water rising from the bottom of the slope and ground condition or the slope stability. Not much work on this particular topic has been done in the state of Sarawak, Malaysia. Sarawak is located on the island of Borneo and receives an annual rainfall of 3500$4000 \mathrm{~mm}$. In tropical countries, especially Malaysia, having seasonal rainfall would allow susceptibility to landslide occurrence. Hence, in this study, a homogenous sand slope model with varied slope angle and soil density was tested for its stability under rising groundwater condition. The rate of water rising in the soil was lower than the permeability of soil as tested using the permeability test. SLOPE/W [9] was used to analyze the safety factor of the tested slope. This study will provide knowledge on occurrence of landslides through generation of pore water pressure induced by increment of groundwater level. Therefore, it is essential in this study to

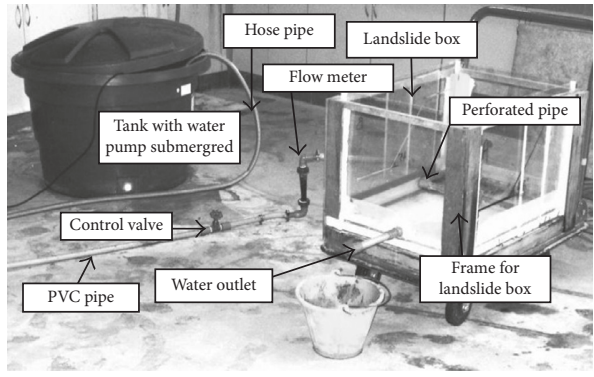

FIGURE 3: Layout of fabricated apparatus.

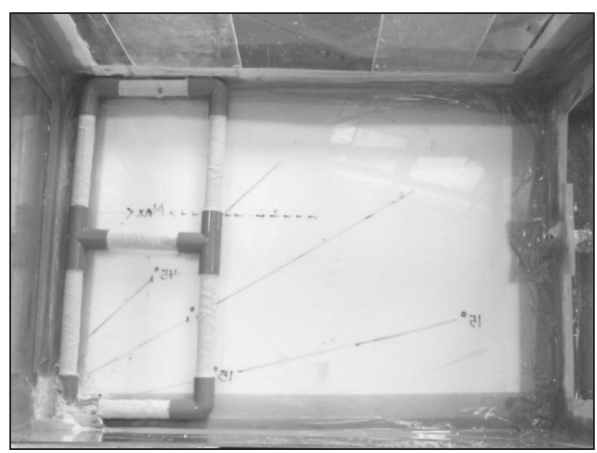

FIGURE 4: Layout of piping to introduce groundwater.

investigate groundwater development and its impact on landslide occurrence.

\section{Materials and Method}

In order to eliminate the infiltration and surface runoff, landslide-triggering factors, water was introduced from the bottom of the slope in this study. Figure 3 shows the overall experimental setup. A perforated pipe was placed at the bottom of the box where water would be induced from the bottom of the slope. Figure 4 shows the location of the piping used to introduce groundwater.

The slope model was prepared in the landslide box $(0.7 \times 0.5 \times 0.4 \mathrm{~cm})$ with different soil densities and angles. The proctor test was conducted to obtain the optimum moisture content and the maximum dry density of sand. From Figure 5, the percentage of the optimum moisture content obtained is $21 \%$, and the maximum dry density is $1635 \mathrm{~kg} / \mathrm{m}^{3}$. However, the density chosen in this study was at $98 \%$ of the maximum dry density $\left(1602 \mathrm{~kg} / \mathrm{m}^{3}\right)$ at which the moisture content was $19 \%$. This choice was made due to the difficulty in attaining $100 \%$ maximum density in the model box. All the varied values of density were chosen based on this new density value which was at $98 \%$ of the maximum density. The permeability at this chosen maximum density was measured to be $1.5 \times 10^{-3} \mathrm{~m} / \mathrm{s}$.

The soil densities were varied by varying the number of compactions applied on the slope using a $4.5 \mathrm{~kg}$ hand compactor, and the slope was shaped to the required angle. Two PVC stand pipes were driven within the top of the slope model for monitoring the water level (Figure 6). A flow 


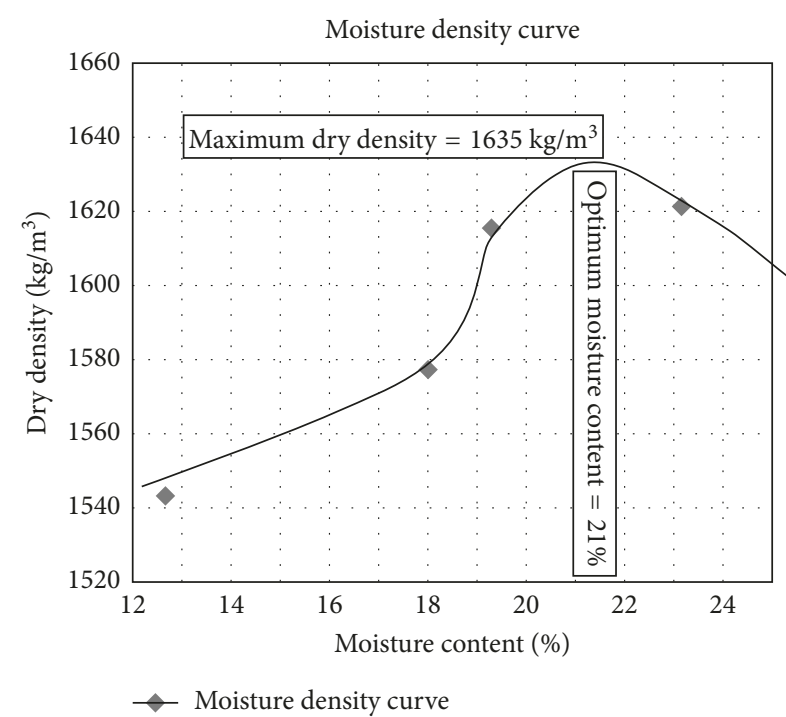

FIgURE 5: Proctor test result for sand used to construct slope model.

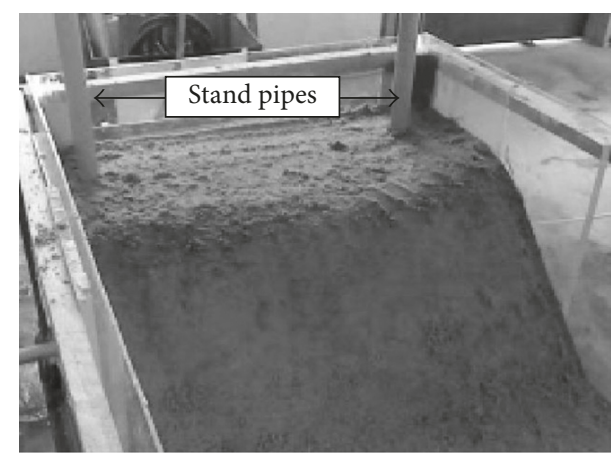

FIGURE 6: PVC stand pipes for water level observation.

meter and a control valve were the control devices in maintaining the required flow rate to be introduced within the slope throughout the experiments. Video cameras were used and located at both sides of the landslide box to capture any physical changes observed in the experiments.

For slope stability analysis, SLOPE/W analysis was performed. The Morgenstern-Price method was utilized in the analysis which satisfies both force and moment equilibrium to evaluate the stability of the slope. In this experiment, the slip surfaces were identified based on physical changes of the tested slope monitored during the test. The developed slip surfaces were included in the determination of the safety factor using SLOPE/W. The factor of safety was computed at initial condition of the slope (no failure), at point of appearance of a minor slip/scarp in the slope, and at existence of a major slip/collapse in the slope. Slips were identified from the video recording attained during the test.

\section{Results and Discussion}

Two parameters were taken into consideration in the study, namely, the soil density and slope angle. Test Condition A involves varied soil density by varying the number of compactions while maintaining the moisture content at 19\%
TABLE 1: Experiments specification.

\begin{tabular}{ccccc}
\hline & Experiment no. & 1 & 2 & 3 \\
\hline & Density $\left(\mathrm{kg} / \mathrm{m}^{3}\right.$ ) & 1523 & 1562 & 1592 \\
& Relative density (\%) & 0 & 50 & 88 \\
& Moisture content (\%) & 19 & 19 & 19 \\
Condition A & Degree of compaction & 32 & 48 & 64 \\
& (per layer) & blows & blows & blows \\
& Strength parameters & $0.14 ;$ & $0.11 ;$ & $0.16 ;$ \\
& $\left(\mathrm{kg} / \mathrm{cm}^{2}\right.$; degree) & 51.77 & 53.13 & 55.49 \\
\hline & Slope angle $($ degree) & 25 & 45 & 60 \\
& Density (kg/m $\left.{ }^{3}\right)$ & 1562 & 1562 & 1562 \\
Condition B & Relative density (\%) & 50 & 50 & 50 \\
& Degree of compaction & 48 & 48 & 48 \\
& $($ per layer) & blows & blows & blows \\
& Strength parameters & $0.11 ;$ & $0.11 ;$ & $0.11 ;$ \\
& $\left(\mathrm{kg} / \mathrm{cm}^{2}\right.$; degree) & 53.13 & 53.13 & 53.13
\end{tabular}

and the slope angle at $45^{\circ}$. The experiment intends to study the pore pressure development in the slope and its safety factor at different densities $\left(1523,1562\right.$, and $\left.1592 \mathrm{~kg} / \mathrm{m}^{3}\right)$. The densities were referred against the $98 \%$ of maximum dry density at $19 \%$ moisture content and were found to be $0 \%$ (loosest condition), 50\% (medium dense), and 88\% (very dense), respectively, in relative density. The minimum density for the calculation of relative density was chosen to be the lowest density value of the tested soil. The direct shear test was also conducted in obtaining the shear strength parameters of the sand samples. The results are tabulated in Table 1. In the other set of experiments, Condition B was introduced in order to investigate the relationship of pore pressure development and safety factors at different slope angles $\left(25,45\right.$, and $\left.60^{\circ}\right)$ while maintaining all soil models at $50 \%$ relative density. Table 1 summarizes the specification of the experiments. Each condition (A or B) was tested for three variations (labeled Experiments 1, 2, and 3).

Figure 7 presents an example of experiments conducted for varied soil density (Condition A). Through a video camera, the observation made is recorded and is shown in Figure $7(a)$ which was then translated into a schematic drawing as shown in Figure 7(b). From the failure pattern, slip surface configuration could be estimated. Based on Figure 7, large displacements of the toe could be observed as it was first introduced to the groundwater. This can be seen in all experiments.

Safety factors were computed in SLOPE/W for its slope stability analysis at three different phases of the slope which are at initial condition, at appearance of a minor slip/scarp, and at collapse (Figure 8). The steps were repeated for a different set of experiments which was performed either using varied soil density or slope angle. Relationship of the safety factor, pore pressure ratio development, and time was then plotted and analyzed.

3.1. Changes in Pore Pressure. Changes in pore water pressure within the slope are based on changes in water level measured in the PVC stand pipes. The bottom of the stand pipes was located aligned with the toe of the slope as the piping to introduce the groundwater was located 


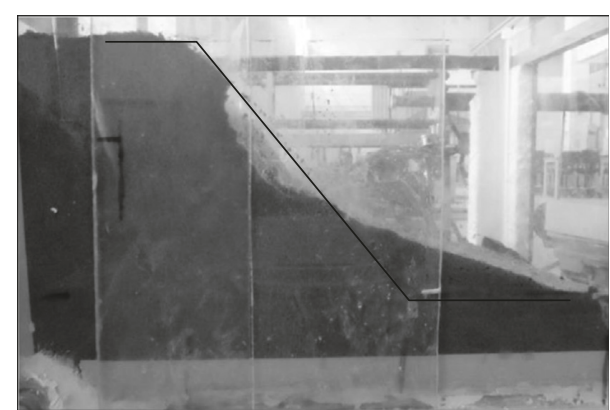

(a)

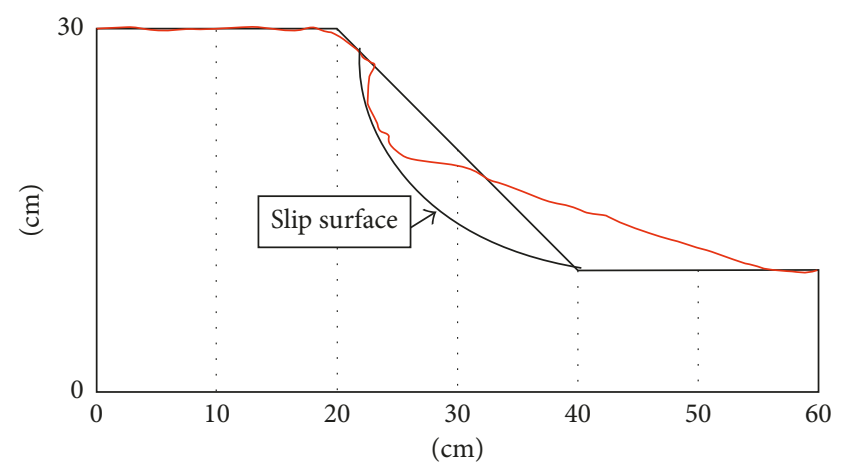

Collapse onset $572 \mathrm{~s}$

_ Sand surface after collapse

_ Original sand surface

(b)

FIgURE 7: Side view of sand slope after collapse in Experiment 1 (varied soil density). (a) Changes of slope surface. (b) Displacement of slope before and after collapse.

immediately at that level. Equation (1) was used to determine the pore water pressure ratio at different water levels. Measured values, considered as the general pore water pressure ratio in the slope, which correspond to the failure condition were input in the SLOPE/W analysis. Table 2 shows the measured pore pressure ratio.

$$
r_{u}=\frac{\mu}{\gamma_{\text {soil }} h}
$$

where $\mu=$ pore water pressure $\left(\mathrm{kN} / \mathrm{m}^{2}\right), \gamma_{\text {soil }}=$ unit weight of soil $\left(\mathrm{kN} / \mathrm{m}^{2}\right)$, and $h=$ thickness layer of overlying soil $(\mathrm{m})$.

3.2. Varied Soil Density (Condition A). Figure 9 presents the factor of safety changes over time in experiments conducted. In general, the safety factor decreases linearly over time until the slope failed or collapsed. For comparison between the experiments, Experiment 3, which has the highest density of sand, shows a slightly higher safety factor value than others in the minor slip and collapse state. In terms of stability, Experiment 3 was better than other experiments; however, a minor slip/landslide occurred faster in Experiment 3, possibly due to faster development of pore water pressure in the slope.

Figure 10 shows increment in pore pressure for higher density sand, particularly in Experiment 3. This is due to the soil being densely compacted and having higher density, and thus, water dissipation is slower which causes the

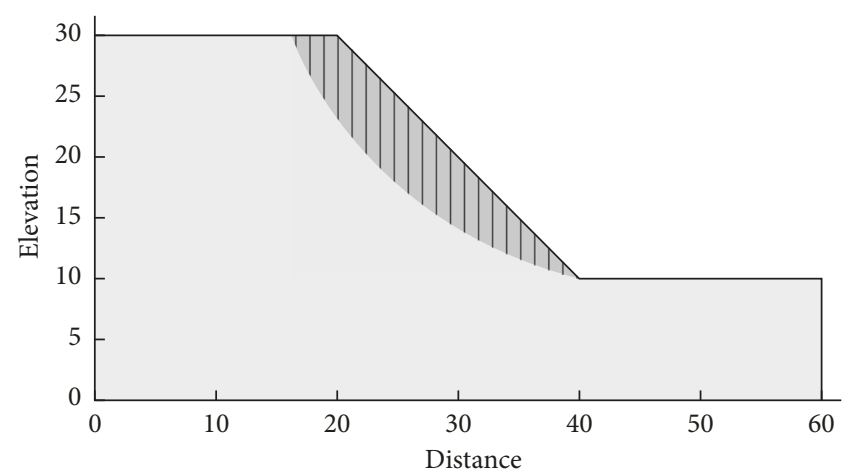

(a)

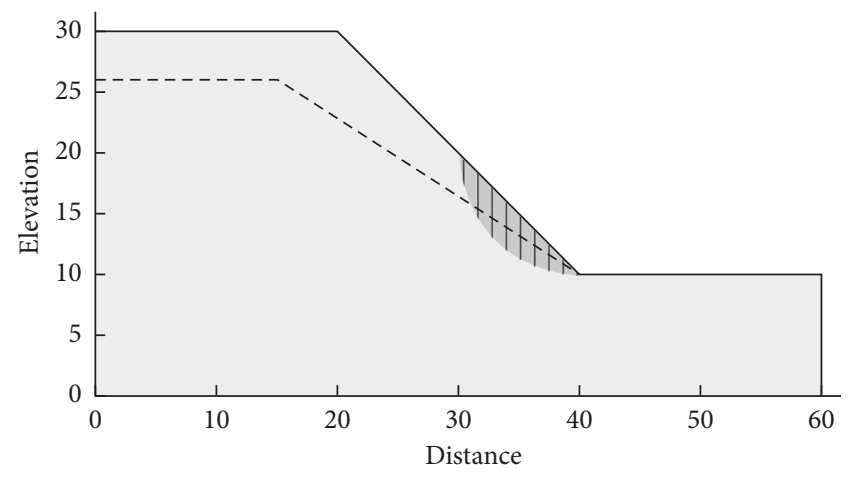

(b)

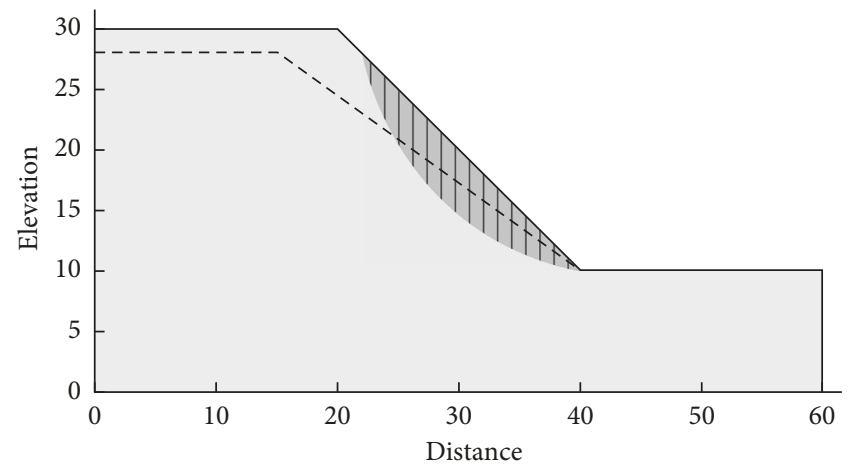

(c)

FIgURE 8: Slope stability analysis of Experiment 1 at collapse state (varied soil density). (a) Initial condition. (b) At appearance of minor slip/scarp. (c) At collapse.

accumulated pore water to increase significantly over time. Wang and Sassa [6] mentioned that generated pore water pressure is dissipated very quickly in soil with greater permeability. It can be concluded that lower density sand generates less pore pressure due to faster dissipation of pore water pressure over time. In addition, the pore water pressure is also observed to have gradually increased before failure after which it rises rapidly until reaching a peak which occurred seconds before failure.

The analysis in Figure 11 is based on safety factors versus pore pressure ratio along the slope toe before start of the experiment, onset of the minor slip, and immediately after collapse of the slope model. The graph shows that the factor of safety decreases with the increase of the pore pressure ratio. From the graph, a sudden drop of the safety factor at 
TABLE 2: Water level and pore pressure ratio onset of minor slip and collapse.

\begin{tabular}{lccccccccc}
\hline Slope feature & \multicolumn{3}{c}{ Experiment 1} & \multicolumn{3}{c}{ Experiment 2 } & \multicolumn{3}{c}{ Experiment 3 } \\
& Time $(\mathrm{s})$ & Water level $(\mathrm{cm})$ & $r_{u}$ & Time $(\mathrm{s})$ & Water level $(\mathrm{cm})$ & $r_{u}$ & Time $(\mathrm{s})$ & Water level $(\mathrm{cm})$ & $r_{u}$ \\
\hline Minor slip/scarp & 486 & 16 & 0.53 & 431 & 15.5 & 0.50 & 288 & 14.5 & 0.46 \\
Collapse & 545 & 18 & 0.59 & 516 & 18 & 0.58 & 361 & 17 \\
\hline
\end{tabular}

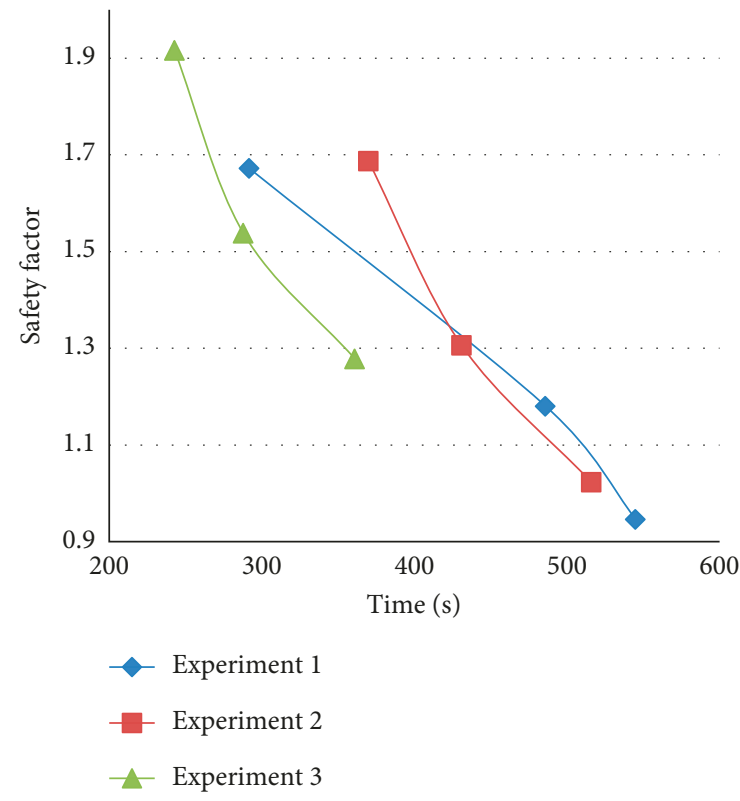

Figure 9: Safety factor against time.

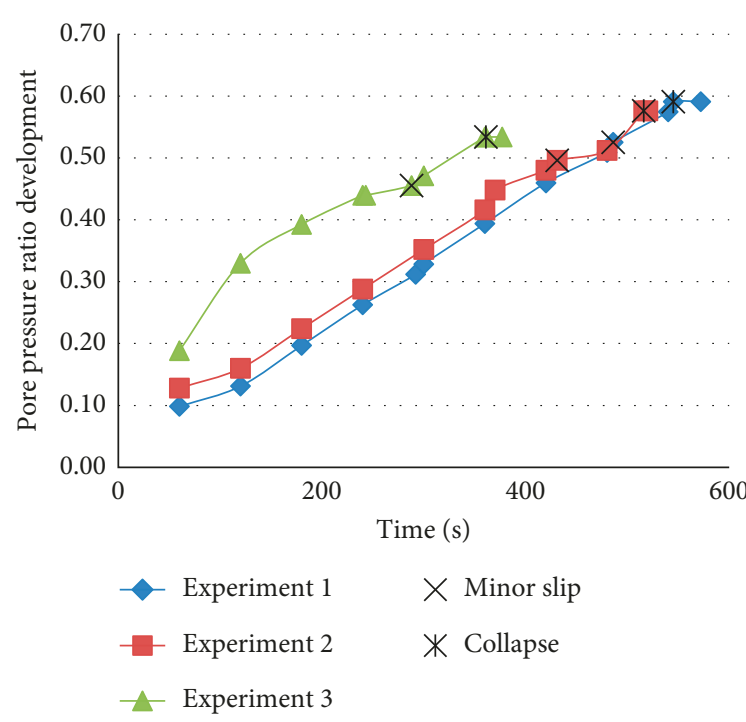

Figure 10: Pore pressure ratio development along toe against time.

onset of the minor slip to the collapse state of the slope or major slip is observed. Rise of water level within the slope had also caused the occurrence of seepage along the slope surface and, together with the increase of the pore pressure ratio over time, resulted in a decrease in the safety factor of the slope.

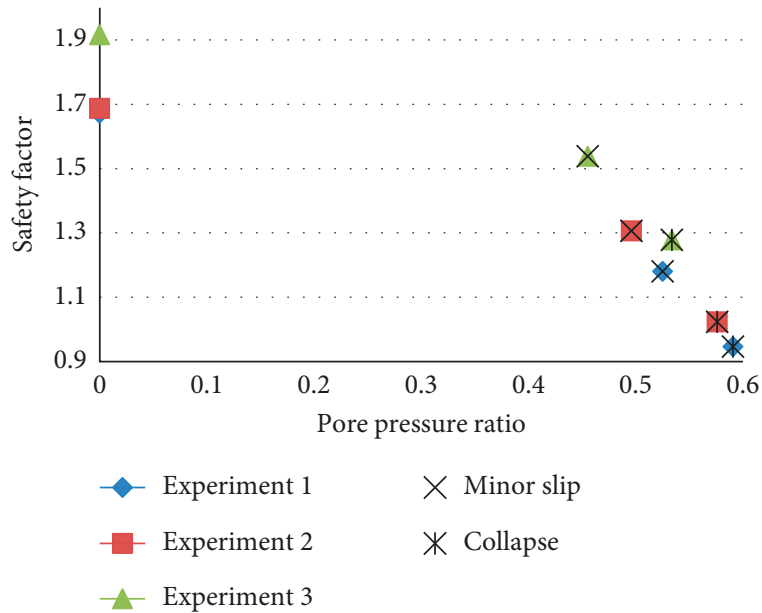

FIGURE 11: Safety factor against pore pressure ratio.

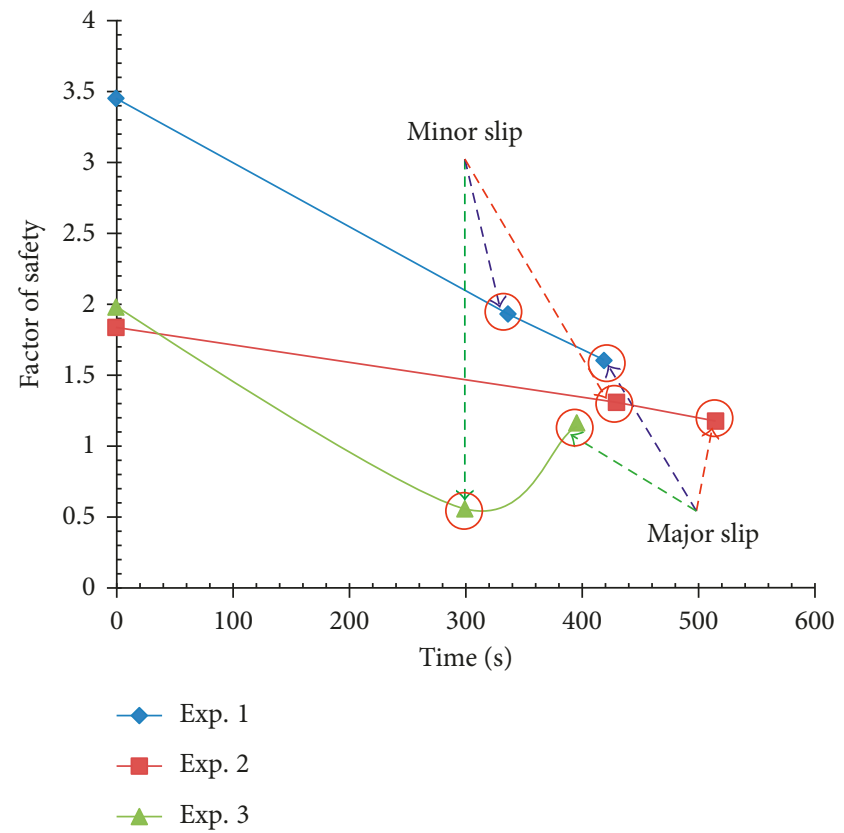

FIGURE 12: Factor of safety against time.

3.3. Varied Slope Angle (Condition B). Figure 12 shows the factor of safety changes over time when the slope angle was varied with the same density of sand. The factor of safety of the slope was gradually decreased over time until the slope failed. From this study, it shows that the smallest slope angle is more stable than the highest slope angle as pore water pressure increases, and the difference in time of failures between the three experiments shows that different slope angles have different time of failures and safety factors 


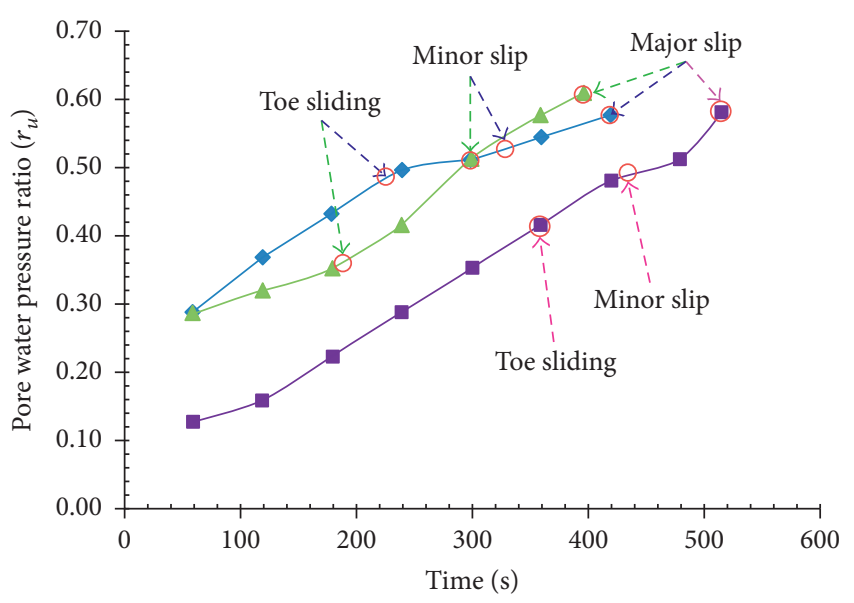

$\rightarrow$ Exp. 1

$\rightarrow$ Exp. 2

$\rightarrow$ Exp. 3

Figure 13: Pore water pressure ratio against time.

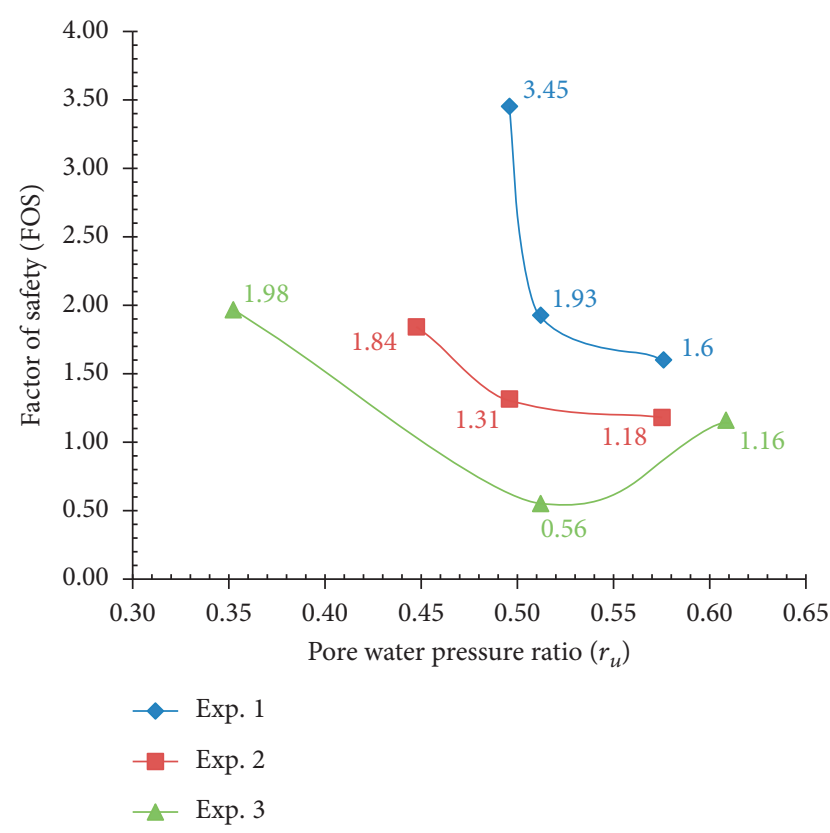

FIGURE 14: Factor of safety against pore water pressure ratio.

during failures when the increment of water level rises in the same rate. As pore water pressure increases, effective stress reduces, and the available shear strength within the soil mass is reduced, thereby decreasing the slope stability [10].

Figure 13 shows that the pore water pressure increases as time increases in the three experiments. This is due to constant water level rising from below the slope. Continuous increment of water from below can cause slope failure. In this case study, it shows that different slope angles affect the time of slope failure onset. The smallest slope angle takes longer time to fail, and in contrast a bigger slope angle takes faster time to fail.

Based on Figure 14, the safety factor decreases when pore water pressure increases. Initial conditions of the experiments have shown the highest safety factor at lower pore water pressure. From initial conditions to minor slip appearance, pore water pressure increases while the safety factor decreases. As soil becomes more saturated, pore water pressure increases, which would, in turn, reduce shearing resistance of the soil. This condition reduces the factor of safety of the slope. Constant rise of water level increases more pore water pressure in soil and causes major slip of the slope models.

\section{Conclusion}

In this study, the pore pressure ratio development along the slope toe increased with time due to increment of water level. Due to increment of water from bottom, the saturation of the toe surface started first, and a slight movement occurred, which led to toe sliding. This movement was followed by minor scarp occurrence near the middle of the slope and then appearance of a major scarp immediately before the collapse. The worst slip can be seen at the lowest sand density and at the steepest slope angle of $60^{\circ}$.

Safety factors of the slope were computed and analyzed using SLOPE/W. From the analysis, the safety factor of the slope gradually decreased over time until the slope failed with increasing pore water pressure. The highest slope angle shows lower safety factor, and in contrast the smallest slope angle shows higher safety factor.

In Condition A where tests were performed using varied sand density (relative density) (1523 (0\%), 1562 (50\%), and $\left.1592(88 \%) \mathrm{kg} / \mathrm{m}^{3}\right)$, it is found that the slope with highest density has higher safety factor, but leads to faster slope failure due to faster development of the pore pressure ratio within the slope. This may happen because of the slower dissipation rate in higher density sand.

Condition $\mathrm{B}$, which is a set of experiments with varied slope angle $\left(25,45\right.$, and $\left.60^{\circ}\right)$, shows that different slope angles could affect the time of slope failure onset. The smallest slope angle takes longer time to fail in contrast to a bigger slope angle which takes faster time to fail.

\section{Conflicts of Interest}

The authors declare that they have no conflicts of interest.

\section{Acknowledgments}

The authors wish to acknowledge the Ministry of Education Malaysia (ERGS/TK03 (01)/1008/2013(05)), Universiti Malaysia Sarawak, and technical staff of Geotechnical Engineering Laboratory for their support and assistance on the project.

\section{References}

[1] Y. A. Khan, H. Lateh, M. A. Baten, and A. A. Kamil, "Critical antecedent rainfall conditions for shallow landslides in Chittagong City of Bangladesh," Environmental Earth Sciences, vol. 67, no. 1, pp. 97-106, 2011.

[2] B. Pradhan and S. Lee, "Delineation of landslide hazard areas on Penang Island, Malaysia, by using frequency ratio, logistic 
regression, and artificial neural network models," Environmental Earth Sciences, vol. 60, no. 5, pp. 1037-1054, 2010.

[3] M. Xie, T. Esaki, and M. Cai, "A time-space based approach for mapping rainfall-induced shallow landslide hazard," Environmental Geology, vol. 46, no. 6-7, pp. 840-850, 2004.

[4] N. Gofar, M. L. Lee, and M. Asof, "Transient seepage and slope stability analysis for rainfall-induced landslide: a case study," Malaysian Journal of Civil Engineering, vol. 18, no. 1, pp. 1-13, 2006.

[5] G. H. Yanusa, A. Kasim, and N. Gofar, "Effect of soil layering on suction distribution in unsaturated residual soil slope," Electronic Journal of Geotechnical Engineering, vol. 19, pp. 9351-9376, 2014.

[6] G. Wang and K. Sassa, "On the pore-pressure generation and movement of rainfall-induced landslides in laboratory fume tests," Progress in Landslide Science, K. Sassa, H. Fukuoka, F. Wang, and G. Wang, Eds., pp. 167-181, Springer, Berlin, Germany, 2007.

[7] B. X. Lu, T. L. Ye, X. H. Zhang, P. Cui, and K. H. Hu, "Experimental and numerical analysis on the responses of slope under rainfall," Natural Hazards, vol. 64, no. 1, pp. 887-902, 2012.

[8] S. S. Gue and Y. C. Tan, Mitigating the Risk of Landslide on Hill Site Development in Malaysia, 2nd World Engineering Congress, Sarawak, Malaysia, 2002.

[9] GEO-SLOPE International Ltd., SLOPE/W User's Guide for Slope Stability Analysis, GEO-SLOPE International Ltd., Calgary, Alberta, Canada, 2012.

[10] T. S. Lee, L. W. Abramson, S. Sharma, and G. M. Boyce, Slope Stabilization and Stabilization Methods, John Wiley \& Sons, Toronto, Ontario, Canada, 2nd edition, 2002. 


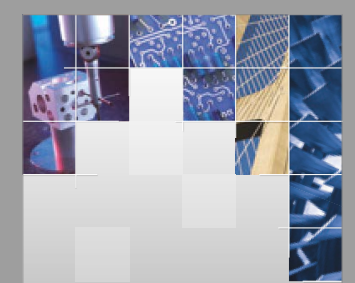

\section{Enfincering}
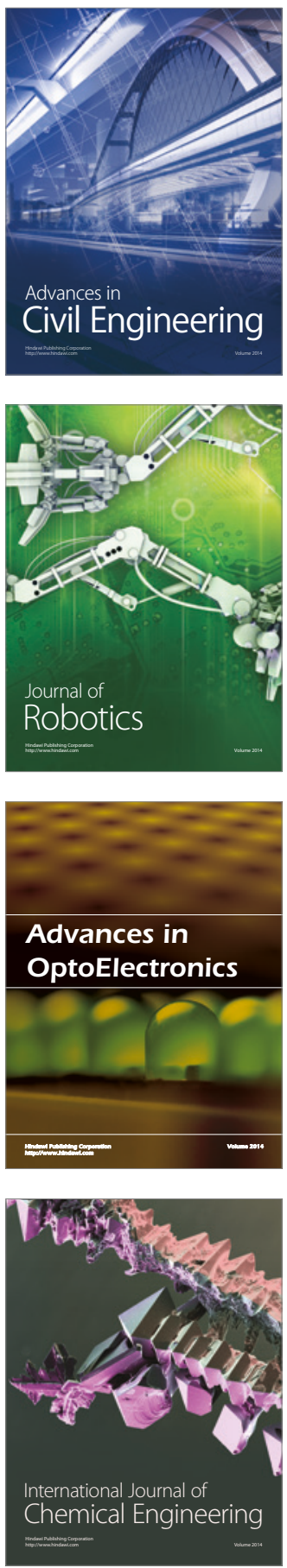

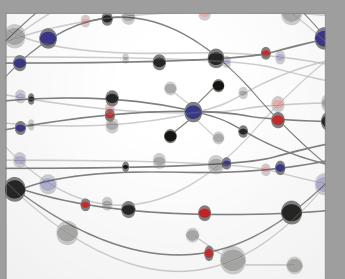

The Scientific World Journal

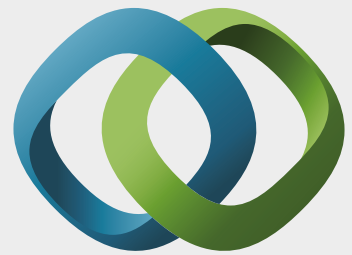

\section{Hindawi}

Submit your manuscripts at

https://www.hindawi.com
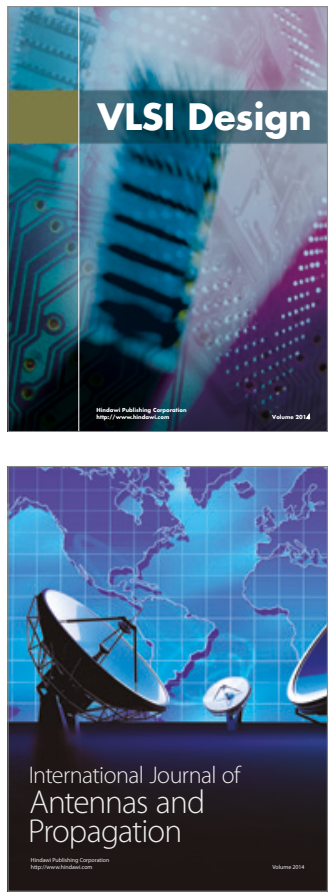

\section{Rotating}

Machinery
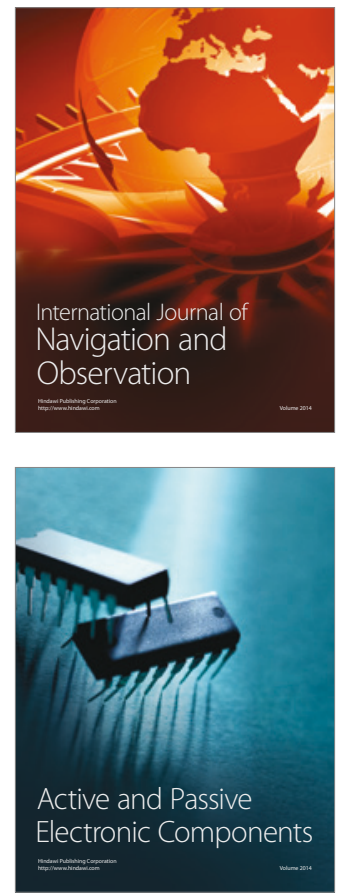
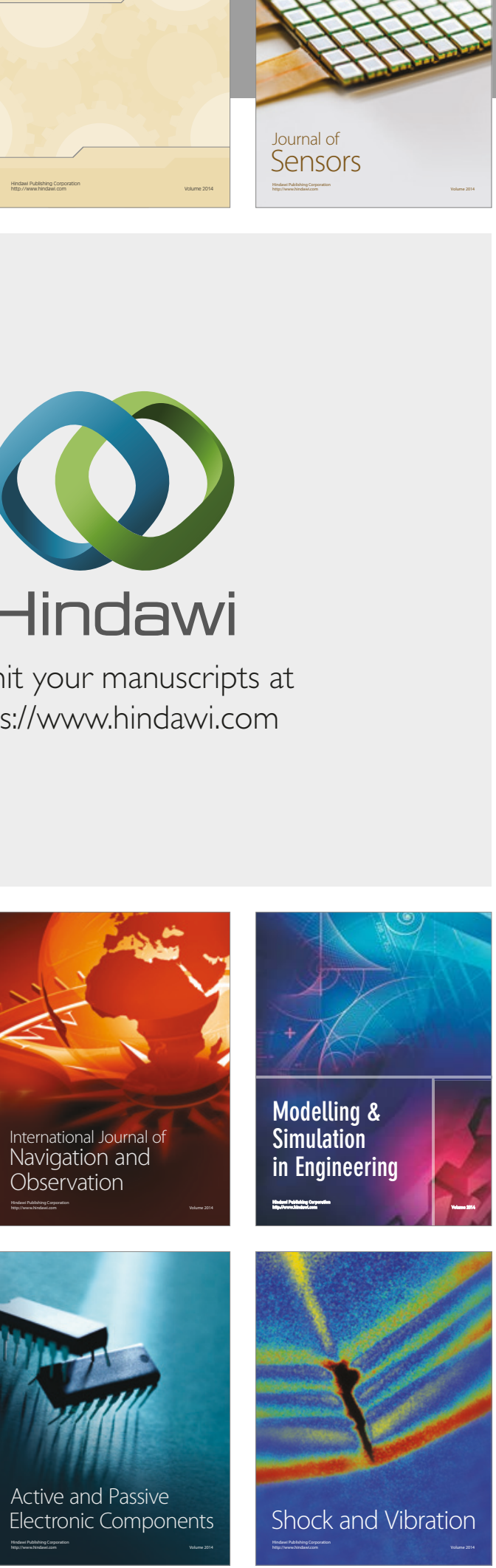
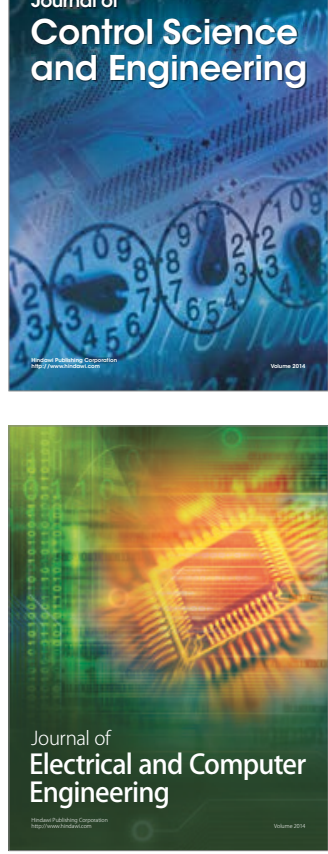

Distributed

Journal of

Control Science

and Engineering
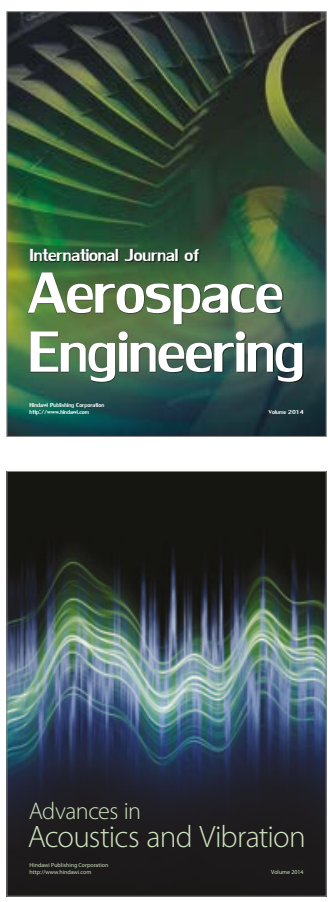

Sensor Networks 